\title{
Smallest detectable differences in clinical variables related to temporomandibular joint arthritis in juvenile idiopathic arthritis
}

\author{
Peter Stoustrup ${ }^{1 *}$, Carlaberta Verna ${ }^{1}$, Kasper D Kristensen ${ }^{1}$, Annelise Küseler ${ }^{1}$, Troels Herlin ${ }^{2}$, Thomas K Pedersen ${ }^{1}$ \\ From 18th Pediatric Rheumatology European Society (PReS) Congress \\ Bruges, Belgium. 14-18 September 2011
}

\section{Background}

Temporomandibular joint (TMJ) arthritis in juvenile patients may lead to craniofacial growth deviations as well as interfere with optimal joint function and mouth opening pattern. Clinical assessment of maximal mouth opening capacity, laterotrusion and protrusion is widely used in the diagnosis of TMJ arthritis as well as in the evaluation of a therapeutic intervention in spite of missing knowledge about the reproducibility of these measurements.

\section{Aim}

To calculate the smallest detectable differences in terms of maximal mouth opening capacity, laterotrusion and protrusion. The smallest detectable difference is the minimal amount of change that can be identified clinically between two consecutive observations.

\section{Methods}

42 patients with juvenile idiopathic arthritis (JIA) were included (mean age 12.8, females $73.8 \%$, previous/current TMJ arthritis 57.1\%). During their clinical orthodontic examinations repeated measurements of maximal mouth opening capacity, laterotrusion and protrusion were conducted by two experienced observers with a calibrated ruler. The measurements were repeated three times by each observer. Intra- and inter-observer variations were calculated. Variance components were identified by analyses-of-variances and used for the calculation of the smallest detectable differences for each of the variables examined.

\section{Results}

The smallest detectable differences found were: maximal mouth opening capacity $7 \mathrm{~mm}$, laterotrusion $3 \mathrm{~mm}$ and protrusion $4 \mathrm{~mm}$. These values were reduced if repeated measurements were conducted. No relationship between the age of the patient and the measurement reproducibility was observed.

\section{Conclusion}

This is the first study to establish guidelines for the detection of genuine changes between separate clinical TMJ examinations in JIA patients.

\section{Author details}

${ }^{1}$ Department of Orthodontics, Faculty of Health Sciences, University of Aarhus, Denmark. ²Department of Pediatrics, Aarhus University Hospital, Aarhus N, Denmark.

Published: 14 September 2011

doi:10.1186/1546-0096-9-S1-P127

Cite this article as: Stoustrup et al:: Smallest detectable differences in clinical variables related to temporomandibular joint arthritis in juvenile idiopathic arthritis. Pediatric Rheumatology 2011 9(Suppl 1):P127.

\footnotetext{
* Correspondence: pstoustrup@odont.au.dk

'Department of Orthodontics, Faculty of Health Sciences, University of

Aarhus, Denmark

Full list of author information is available at the end of the article
} 